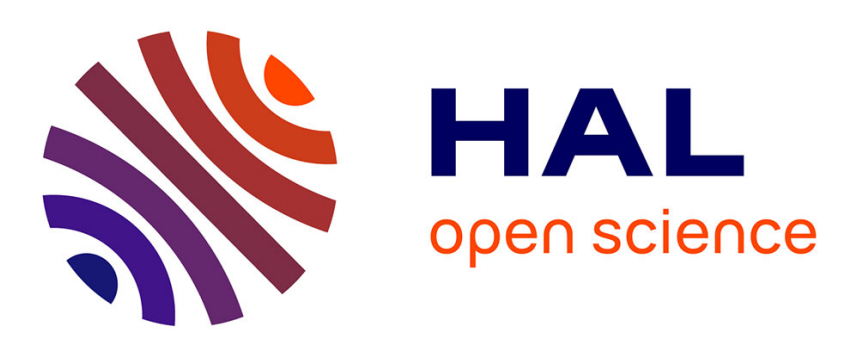

\title{
The development of consonant and lexical-tone discrimination between 3 and 6 years: Effect of language exposure
}

Laurianne Cabrera, Ranka Bijeljac-Babic, Josiane Bertoncini

\section{- To cite this version:}

Laurianne Cabrera, Ranka Bijeljac-Babic, Josiane Bertoncini. The development of consonant and lexical-tone discrimination between 3 and 6 years: Effect of language exposure. International Journal of Bilingualism, 2018, pp.136700691878107. 10.1177/1367006918781077 . hal-01968903

\section{HAL Id: hal-01968903 \\ https://hal.science/hal-01968903}

Submitted on 3 Jan 2019

HAL is a multi-disciplinary open access archive for the deposit and dissemination of scientific research documents, whether they are published or not. The documents may come from teaching and research institutions in France or abroad, or from public or private research centers.
L'archive ouverte pluridisciplinaire HAL, est destinée au dépôt et à la diffusion de documents scientifiques de niveau recherche, publiés ou non, émanant des établissements d'enseignement et de recherche français ou étrangers, des laboratoires publics ou privés. 


\section{The development of consonant and lexical-tone discrimination between 3 and 6 years: effect of language exposure.}

Laurianne Cabrera ${ }^{1,2}$, Ranka Bijeljac-Babic ${ }^{2,3}$ and Josiane Bertoncini²

${ }^{1}$ Speech, Hearing and Phonetic Science department, University College London, London, UK

${ }^{2}$ Laboratoire de Psychologie de la Perception, Université Paris Descartes-CNRS, Paris, France

${ }^{3}$ Université de Poitiers, France

Accepted for publication in International Journal of Bilingualism.

Online version available here:

http://journals.sagepub.com/doi/full/10.1177/1367006918781077

Corresponding author: laurianne.cabrera@parisdescartes.fr

Laboratoire de Psychologie de la Perception, Université Paris Descartes, 45 rue des Saints-Pères, 75006, Paris, France.

Email: laurianne.cabrera@parisdescartes.fr 


\section{Abstract}

Aims and Objectives. The present study explored children's discrimination capacities for lexical tones and consonants between 3 and 6 years of age and the effect of native language on this ability. Recent studies in infants have shown a perceptual rebound for non-native listeners during the second year of life, but only for lexical tones. However, the later stages of development, and particularly when children start preschool, are yet not clear.

Design. Discrimination abilities of 134 children were measured in three age groups between 3 and 6 years using a behavioral task where children detected a change in lexical tones or consonants. Children were either French monolinguals, French bilinguals exposed to an Asian tone language, or French bilinguals exposed to a second non-tone language at home.

Data and Analysis. Overall, results indicated that higher detection scores for consonants were observed from 4-5 years, while for lexical tones the highest scores were observed only at 5-6 years. Moreover, bilingual children exposed to an Asian tone language had higher scores for tones compared to monolingual French children. Interestingly, both bilingual groups, whether exposed to an Asian tone language or to a non-tone language, had better scores for tones than for French consonants, while monolinguals performed equally with both.

Conclusions. Language exposure from an early age influences phonological development and bilingualism seems to enhance the perception of prosodic information.

Originality. This study is the first to show a different developmental trajectory for consonant and lexical-tone discrimination between 3 and 6 years according to the native language.

Significance. Similar detection scores for tones and consonants for monolingual French children, and better detection for tones than for consonants for both groups of bilinguals suggest that the perception of lexical tone is determined by both language-specific influences and non-linguistic/auditory processing during childhood.

Keywords: lexical tones, consonants, childhood, bilinguals, discrimination 


\section{INTRODUCTION}

Understanding the influence of language exposure on phonological development is of fundamental importance in comprehending the mechanisms involved in speech perception and language acquisition. In our multilingual world, more than $50 \%$ of children are exposed to several languages (Grosjean, 2010). These children must, among other things, learn several different phonological repertoires. We know that with exposure to a language, children become better at discriminating the speech contrasts of this language, but they do not show the same improvement for non-native speech contrasts. However, bilingual children exposed to both a tone and a non-tone language must learn that pitch contrasts play different functions in each of their languages. The purpose of the current study was to investigate how phonological development is influenced by exposure to one, or several languages, focusing particularly on tone language. Lexical tone is both a segmental feature, in its linguistic function, and a suprasegmental, or prosodic, feature, by nature (see Burnham \& Mattock, 2007). The two primary acoustic cues differentiating tones are variations in the fundamental frequency level (F0; high, middle, low), and F0 contour variations (steady, rising, falling; e.g., Gandour, 1981; Gandour \& Harshman, 1978; Khouw \& Ciocca, 2007; Vance, 1976). Being both a segmental and a suprasegmental feature, the status of lexical tone in speech perception, and its functional similarity with consonants, is still an open question (see Burnham \& Mattock, 2007). The current experiment aimed to compare the perceptual development of tones and consonants between 3 and 6 years of age to help to understand the influence of the native language or languages, on phonological development.

The perception of consonants and lexical tones in infancy has been extensively explored. During the first year of life, infants begin to tune in to the speech contrasts present in their native language. The perception of consonants in a native-like fashion has been demonstrated after 8 months of age (e.g., Kuhl, Williams, Lacerda, Stevens, \& Lindblom, 1992; Kuhl et al., 2006; Polka \& Werker, 1994; Werker \& Tees, 1984 ). For lexical tones, the same pattern has been observed at around the same age. Infants from a non-tone language background show a perceptual decline for non-native tones between 6 and 9 months, while infants from a tone language background do not show any decline for the same tone contrasts at the same age (Cabrera et al., 2015; Mattock \& Burnham, 2006; Mattock, Molnar, Polka, \& Burnham, 2008; Yeung, Chen, \& Werker, 2012). However, a perceptual rebound for lexical-tone perception has recently been observed in the second year of life for non-native infants (Liu \& Kager, 2014). Dutch infants of 1718 months have been shown to be able to discriminate a non-native lexical-tone contrast, suggesting that lexical-tone perception is plastic and probably driven by non-speech processing of pitch information. Such a rebound effect has not been observed for consonants (e.g., Werker \& Tees, 1983). Thus, it appears that the perception of consonants and lexical tones may not follow the same developmental trajectory during early development. 
Few studies have compared performance of native and non-native children in discriminating consonants and lexical tones during later stages of development. However, the preschool period, between 3 and 6 years, is critical for speech development. At this age, children have received a considerable exposure to their native language, have developed a lexicon, and start to learn to read and write, which probably also affects phonological processing (Bertelson, Gelder, Tfouni, \& Morais, 1989). Little is known about this developmental period and previous studies have shown that 4-yearold English children seem to be less sensitive to non-native lexical tone variations than Thai children (Burnham \& Francis, 1997). At the neural level, the mechanisms involved in consonant and lexical tone detection seem to be different in preschool Mandarin children. The morphology and latency of the neural responses to a change in Mandarin consonants and lexical tones are different, probably due to the specific acoustic characteristics of these features. Moreover, these mechanisms are still developing in preschool and school-aged children (Liu, Chen, \& Tsao, 2014) . Indeed, for lexical processing in children, Burnham et al. (2011) showed that phonological awareness develops earlier than tonological awareness. In this study, children aged 4 to 11 years and adults were asked to detect an odd word among three, in which the word either differed in vowel or tone. Results showed that performance was better for changes on the vowel than tone, suggesting that tones are not taken into account during the early stages of auditory lexical access. Moreover, tonological awareness was superior in listeners exposed to a tone language than those using a non-tone language. Thus, the perception of consonants and lexical tones may also not follow the same trajectory in later stages of speech development. It is important to note though, that adult speakers using non-tone languages are also able to discriminate lexical tones, but do not rely on the same acoustic information compared to tone-language adult speakers (e.g., Bent, Bradlow, \& Wright, 2006; Cabrera, Tsao, Gnansia, Bertoncini, \& Lorenzi, 2014; Hallé, Chang, \& Best, 2004). The difference in perception of lexical tones and consonants during development may therefore be related to the nature of the perceptual mechanisms involved, as the perception of lexical tones seems to be determined by both language-specific influences and non-linguistic processing of pitch information.

The present study further explored the ability of children aged between 3 and 6 years to discriminate lexical tones and consonants, as the effect of age and language exposure on phonological development is not yet fully understood. It is also worth noting that at this age children entering pre-school, starting at 3 years in France, who are not exposed to French at home, may start a more formal learning of this language.

This study also aimed to investigate the effect of exposure to one, or more languages, including exposure to a tone language, on the perception of consonants and lexical tones. Previous studies with infants have shown that bilingual infants not previously exposed to a tone language exhibit perceptual rebound for lexical tones earlier than their monolingual peers, at 11-12 months (Liu \& Kager, 2017). Thus, being exposed to various languages, even ones which do not use lexical tone, seems to improve the perception of tones. Similar results have also been observed in a word learning task for bilingual English-Mandarin children at 17 months who were more sensitive to a Thai 
non-native lexical tone contrast than their monolingual Mandarin peers (Burnham, Singh, Mattock, Woo, \& Kalashnikova, 2017). In other studies comparing the effect of consonant, vowel and lexical-tone mispronunciation on word learning abilities, language-specific processing of lexical tone was observed only at 2 years of age (Singh, Goh, \& Wewalaarachchi, 2015; Singh, Hui, Chan, \& Golinkoff, 2014). At 18 months, English monolinguals, Mandarin-English bilinguals, and bilinguals exposed to English and another non-tone language were able to detect a mispronunciation on lexical tone and vowel in a word learning task. However, at 24 months, only the Mandarin-English bilinguals were able to do so for the lexical-tone mispronunciation. Similar differences in performance between monolinguals and bilinguals have also been observed for other suprasegmental features; Bilingualism in infants has been related not only to a better ability to distinguish between segmental phonemic contrasts of both languages but also between lexical-stress (e.g., Bijeljac-Babic, Serres, Höhle, \& Nazzi, 2012; Burns, Yoshida, Hill, \& Werker, 2007; Sundara, Polka, \& Molnar, 2008). For instance, infants exposed to both French that does not use lexical stress pattern, and to another language using stress at the lexical level, showed better stress discrimination abilities than French monolinguals at 10 months. This difference between bilinguals and monolinguals has been observed in the context of high segmental variability, where different words show the same prosodic pattern (Abboub, Bijeljac-Babic, Serres, \& Nazzi, 2015). It has been proposed that exposure to numerous languages enhances sensitivity to prosodic cues at an abstract, phonological level (Bijeljac-Babic et al., 2012, but see also Skoruppa et al., 2009). Comparing lexical-tone and consonant perception in bilinguals and monolinguals is one way to explore how the perceptual mechanisms for segmental and suprasegmental features are shaped by language exposure.

The present study assessed the perception of Thai lexical tones and French consonants in monolingual French children, bilingual children exposed to a tone language at home, and children exposed to a non-tone second language at home by using two behavioral phonetic discrimination tasks. The aim of the present study was two-fold: i) to compare how children perceive lexical tones and consonants between 3 and 6 years of age, ii) to assess the effect of exposure to a tone language on the ability to perceive these two types of phonological contrasts.

Given previous studies on phonetic discrimination in infants and word learning in toddlers, it was expected that consonant and tone discrimination would not follow the same developmental trajectory between 3 and 6 years for all children. Specifically, lexical tone changes are expected to be easier to perceive than consonantal differences as they incorporate both segmental and suprasegmental variation (e.g., Liu \& Kager, 2017). Moreover, the children's native language background was also expected to influence the perception of consonants and lexical tones (even when bilingual children had been exposed to a different tone language). One possibility is that children exposed to a tone language at home will be better at perceiving lexical tones than French consonants in the present task. Another possibility is that children exposed to a second non-tone language will also show better perception of lexical tones compared to 
monolinguals as their perception of prosodic cues may be enhanced by exposure to numerous languages.

\section{METHOD}

\section{Participants}

Data from 134 children were collected from three different kindergarten schools in Paris. Three age groups, corresponding to the three classes, were tested: 3-4 years ( $\mathrm{N}=35,18$ girls), 4-5 years ( $\mathrm{N}=50,21$ girls), 5-6 years $(\mathrm{N}=49,22$ girls). Data from 14 additional children were excluded because they could not perform the tasks (12 children from the 3-4 year section, 1 child from the 4-5 year section, and 1 from the 5-6 year section). The study was approved by the local university ethics committee and written consent forms were obtained from the parents before the experiment.

The languages spoken by the children were evaluated through a parent questionnaire. This questionnaire aimed to identify the main languages used in the child's everyday life. Parents indicated the main two languages spoken in six situations: by each parent individually (parent 1 , parent 2), by the parents when speaking to each other, by the parents when speaking to the child and siblings, by the children themselves, and overall in the house with friends and family. Based on this data, a measure of the proportion of exposure to French, an Asian tone-language (such as Mandarin, Cantonese, Vietnamese or Thai), and any other languages was then computed for each child. This questionnaire revealed that 55 children out of 134 were French monolinguals, that is, only exposed to French at home, 14 were only exposed to an Asian tone language, and 2 children were only exposed to a language that was not French or Asian tone. Among the bilingual children, 31 were exposed to an Asian tone language at home and 35 to a nontone language ( 3 children were exposed to both an Asian tone and another non-tone language). Figure 1 displays the proportion of these 3 language types for the 3 groups of children. 


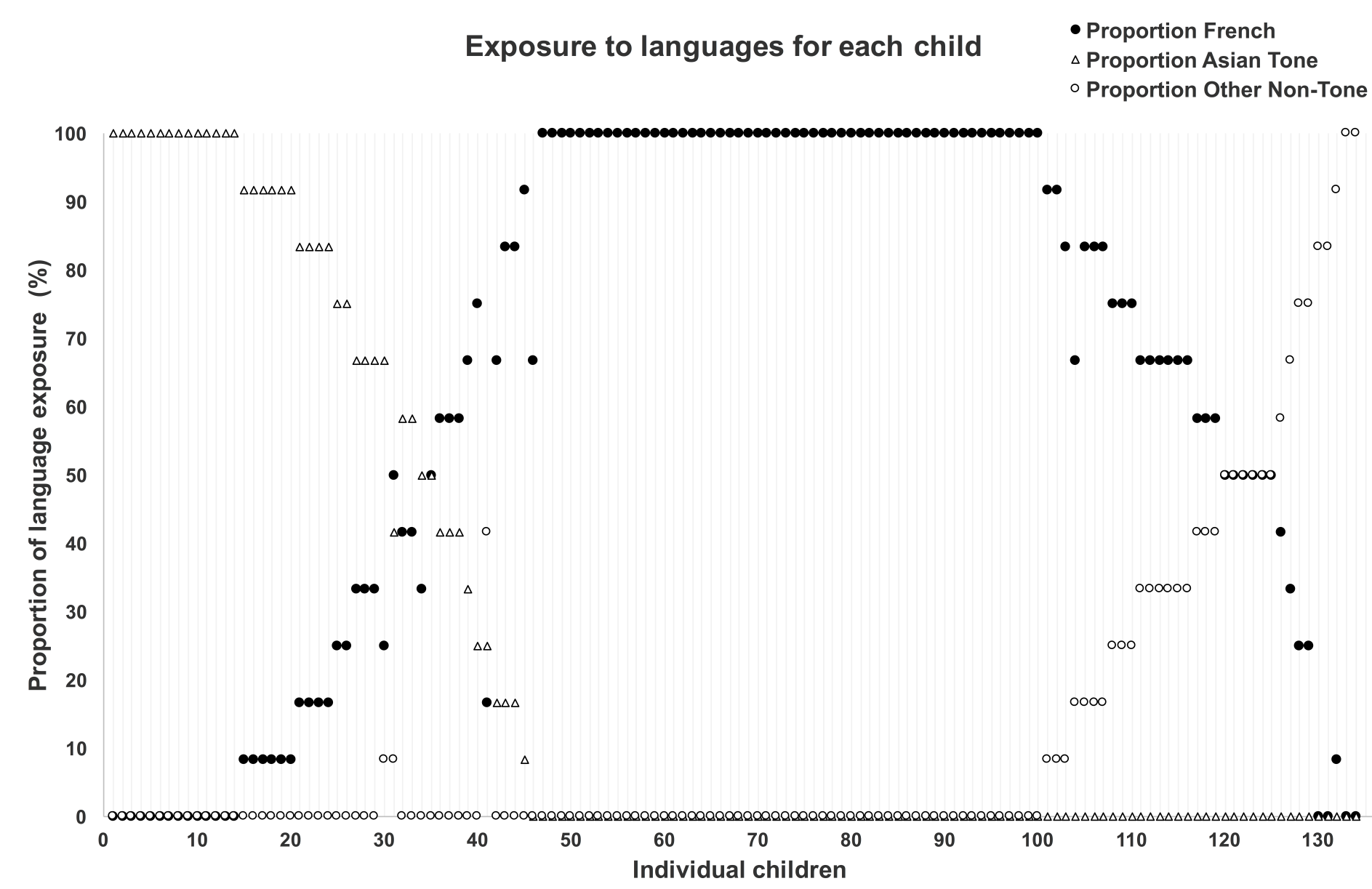

Figure 1. Proportion of language exposure (filled circle for French, open triangle for any Asian tone language, open circle for any other non-tone language) for each child. 


\section{Stimuli}

The stimuli were recorded in a soundproof room, and digitized via a 16-bit analog-to-digital converter at a $44.1-\mathrm{kHz}$ sampling rate. Intensity of each stimulus was equalized.

Two French contrasts were used: a voicing (/aba/-/apa/) and a place of articulation (/aba/-/ada/) contrast. French voicing contrasts involve voiceless consonants, with a $\sim 0$ ms voice onset time (VOT), and pre-voiced consonants, with negative VOT values indicative of glottal action preceding the stop burst (i.e., Ryalls \& Larouche, 1992; Caramazza \& Yeni-Komshian, 1974; Serniclaes, 1987) . In French, stop consonants are non-aspirated, that is, there is no air burst after consonantal release prior to vocal cord vibration (e.g., Cho \& Ladefoged, 1999). Such phonological characteristics could be unfamiliar for children mainly exposed to Mandarin Chinese or Cantonese that use aspirated voiceless versus non-aspirated voiceless contrasts (Zhang, 2012).

Eight exemplars of /aba/, and four exemplars of /apa/ and /ada/ were selected from a set of vowel-consonant-vowel (VCV) nonsense bisyllables produced by a French female speaker (mean F0 $=254 \mathrm{~Hz}, \mathrm{~F} 0$ range $=212-294 \mathrm{~Hz}$ ) who was asked to speak clearly. The stimuli were not significantly different in duration $(p>.05$ for the background category versus each target category). Table 1 summarizes the VOT characteristics (time between the consonant release and voicing), duration, and pitch range of the French VCVs.

Two Thai lexical tone contrasts were also used: a contour-contour (rising tonefalling tone) and a contour-level (rising tone-low tone) contrast. Three lexical tones were recorded from a Thai female speaker (see Cabrera et al., 2014; Mattock \& Burnham, 2006). A rising tone was contrasted in contour with a falling tone, and was also contrasted in level with a low tone (showing similar F0 trajectories until the mid-point of the tone). Even though these Thai tones are non-native for non-Thai listeners from another Asian tone language background (e.g., Mandarin or Cantonese), non-Thai infants and adult listeners are still able to discriminate them (see Cabrera et al., 2015; Mattock \& Burnham, 2006).

Eight exemplars of /ba/ with a rising tone (i.e., rising F0 trajectory), four exemplars of /ba/ with a falling tone (i.e., falling F0 trajectory), and four exemplars of /ba/ with a low tone (i.e., steady F0 trajectories) were selected from a set of CV nonsense syllables produced by a female native speaker of Thai language (mean F0=207 $\mathrm{Hz}, \mathrm{F} 0$ range $=100-350 \mathrm{~Hz}$ ). The duration of the tone stimuli did not differ significantly between the 3 categories $(p>.05)$. Table 2 summarizes the VOT characteristics, duration and pitch range of the Thai CVs. 


\begin{tabular}{|c|c|c|ll|}
\hline $\begin{array}{c}\text { French } \\
\text { VCVs }\end{array}$ & VOT (ms) & \multicolumn{2}{|c|}{$\begin{array}{c}\text { Total } \\
\text { duration (ms) }\end{array}$} & Pitch range (Hz) \\
\hline & $\mathbf{1 .}-210$ & $\mathbf{1 .} 593$ & $\mathbf{1} .215 .7-292.1$ \\
& $\mathbf{2 .}-253$ & $\mathbf{2 .} 685$ & $\mathbf{2 .} 212.6-293$ \\
/aba/ & $\mathbf{3 .}-252$ & $\mathbf{3 .} 691$ & $\mathbf{3 .} 212.8-286.6$ \\
background & $\mathbf{4 .}-236$ & $\mathbf{4 .} 692$ & $\mathbf{4 .} 216.7-291.8$ \\
& $\mathbf{5 .}-188$ & $\mathbf{5 .} 659$ & $\mathbf{5 .} 221.2-284.9$ \\
& $\mathbf{6 .}-207$ & $\mathbf{6 .} 646$ & $\mathbf{6 .} 216.2-288.9$ \\
& $\mathbf{7 .}-191$ & $\mathbf{7 .} 624$ & $\mathbf{7 .} 216.8-278$ \\
& $\mathbf{8 .}-174$ & $\mathbf{8 .} 624$ & $\mathbf{8 .} 250-283.1$ \\
\hline & $\mathbf{1 .}+10$ & $\mathbf{1 .} 619$ & $\mathbf{1 .} 234.7-288.2$ \\
& $\mathbf{2 .}+8$ & $\mathbf{2 .} 690$ & $\mathbf{2 .} 245-281.9$ \\
& $\mathbf{3 .}+8$ & $\mathbf{3 .} 571$ & $\mathbf{3 .} 235.5-269.6$ \\
& $\mathbf{4 .}+13$ & $\mathbf{4 .} 656$ & $\mathbf{4 .} 235.3-278.7$ \\
\hline & $\mathbf{1 .}-212$ & $\mathbf{1 .} 610$ & $\mathbf{1 .} 219.6-285.9$ \\
& $\mathbf{2 .}-210$ & $\mathbf{2 .} 612$ & $\mathbf{2 .} 220-286$ \\
& $\mathbf{3 .}-347$ & $\mathbf{3 .} 693$ & $\mathbf{3 .} 213.9-294.3$ \\
& $\mathbf{4 .}-395$ & $\mathbf{4 .} 664$ & $\mathbf{4 .} 214.4-292.4$ \\
\hline
\end{tabular}

Table 1. Characteristics of the French Vowel-Consonant-Vowel (VCV) syllables recorded from a female speaker: Voice Onset Time (VOT, in ms), Total duration (in ms) and Pitch range (in $\mathrm{Hz}$ ). For the background category, 8 exemplars were selected and only 4 for the change category. The average fundamental frequency is $254 \mathrm{~Hz}$, the first vowel is always higher in pitch than the second one.

\begin{tabular}{|c|c|c|c|}
\hline Thai CVs & VOT (ms) & $\begin{array}{c}\text { Total } \\
\text { duration (ms) }\end{array}$ & Pitch range $(\mathrm{Hz})$ \\
\hline \multirow{8}{*}{$\begin{array}{l}\text { /ba/ rising } \\
\text { background }\end{array}$} & 1. -13 & 1. 656 & 1. $138.3-322$ \\
\hline & 2. -15 & 660 & 2. $134.8-340.5$ \\
\hline & 3. -17 & 664 & 3. $137.7-328.4$ \\
\hline & 4. -12 & 642 & 4. $137.7-332.9$ \\
\hline & 5. -17 & 733 & 5. $140.9-349.1$ \\
\hline & 6. -12 & 636 & 6. $140.5-326.6$ \\
\hline & 7. -12 & 630 & 7. $144.8-314.8$ \\
\hline & 8. -12 & 672 & 8. $142.8-321.9$ \\
\hline \multirow{4}{*}{ /ba/low } & 1. -14 & 1. 626 & 1. $105.4-155.7$ \\
\hline & 2. -14 & 2. 605 & 2. $98.55-145.2$ \\
\hline & 3. -14 & 3. 610 & 3. $110-167.9$ \\
\hline & 4. -15 & 4. 620 & 4. $105.9-146.3$ \\
\hline \multirow{4}{*}{ /ba/ falling } & 1. -14 & 1. 575 & 1. $197.37-280.4$ \\
\hline & 2. -7 & 2. 478 & 2. $223.3-285.2$ \\
\hline & 3. -11 & 3. 557 & 3. $100-277.3$ \\
\hline & 4. -10 & 4. 496 & 4. $197.5-274.8$ \\
\hline
\end{tabular}

Table 2. Characteristics of the Thai Consonant-Vowel (CV) syllables recorded from a female speaker: Voice Onset Time (VOT, in ms), Total duration (in ms) and Pitch range (in $\mathrm{Hz}$ ). For the background category, 8 exemplars were selected and only 4 for the change category. The average fundamental frequency is $207 \mathrm{~Hz}$. 


\section{Procedure}

Children's ability to discriminate lexical-tone and consonant contrasts was measured using a discrimination task adapted from the Visual Reinforcement Assessment of the Perception of Speech Pattern Contrasts (VRASPAC, e.g., Eisenberg, Martinez, \& Boothroyd, 2004) procedure. This procedure combines different behavioral procedures generally used with infants (repeated auditory background) and older children (Change/No-Change procedure) to measure speech and auditory perception abilities in toddlers (e.g., Eisenberg et al., 2004; Holt \& Lalonde, 2012; Martinez, Eisenberg, Boothroyd, \& Visser-Dumont, 2008) and children before 6 years (Bertoncini, Serniclaes, \& Lorenzi, 2009).

Children were tested individually in a quiet room at school. Each child sat in front of a screen displaying a colorful background picture while listening to a repeated background stimulus presented through two loudspeakers located on each side of the screen and playing sounds at around $70 \mathrm{~dB}$ SPL. Children were asked to press a response button as accurately and as fast as they could when (and only when) a change occurred within the continuously repeated sequence of speech stimuli. They were instructed to get ready with their hands above the response button. Each trial was launched by the experimenter, seated next to the child, when the child was judged to be ready - that is, when she/he was looking at the background picture. The experimenter was unaware of the nature of the upcoming trial, but did not wear any headphones in order not to distract the child. Each trial was composed of four exemplars of either the same category as the background stimulus ("no change" trials), or four exemplars of a different category ("change" trials). Ten change trials (5 trials for each contrasting stimuli) and the 5 no-change trials were presented in a random order within each condition (Consonant and Lexical tones). No-change trials were used to assess response bias of the listeners. The silent inter-stimulus interval varied randomly in duration between 450 and $1200 \mathrm{~ms}$ during the presentation of the background stimulus as well as during the presentation of both change and no change trials. Thus, no change in stimulus duration or in silent interval duration could be used to detect a change in the repeated stimuli during change trials. The child had to react to the occurrence of the contrasting stimulus within the duration of the "change" trial (that included the four exemplars of one change syllable, from the onset of the first exemplar and the offset of the last exemplar). Each trial ended either when the child made a correct response even before the end of the four exemplars or when the child did not respond within the duration of the four exemplars. Correct responses were reinforced by the presentation of one picture of a colorful character (award figure) on the screen; misses (no response given by the end of the change trial) and false alarms (responses during a no change trial) were followed by a "negative" emoticon. At the end of a trial, the repeated stimulus was restarted. Any response given under $100 \mathrm{~ms}$ following the onset of the change was not counted as a hit.

After a short training phase in which children had to discriminate between 2 syllables varying in phonemes and contours /ko/ and /mi/, each child completed a 
single test session with two conditions (Consonant and Lexical tones) that lasted around 10 mins. The order of the two conditions was counterbalanced between participants. The background stimulus in the consonant condition was the syllable /aba/, and in the lexical tone condition the syllable /ba/ with a rising tone. The change syllables in the consonant condition were either /ada/ or /apa/, and in the lexical-tone condition either /ba/ falling or /ba/ low. Response accuracy was recorded for both the change trials and the no-change trials for each contrast type (Consonants versus Tones).

\section{RESULTS}

First, an analysis of children's response accuracy for change trials and no-change trials was conducted. Children were split into 3 groups based on their repeated language exposure: i) only to French $(\mathrm{N}=55)$, ii) to an Asian tone language at home (that is, any proportion of exposure above $0 \% ; \mathrm{N}=45$ ), iii) to any other non-tone language (that is, absence of exposure to any Asian tone language, $\mathrm{N}=34$ ). In the group of 3-4-year-old children, this gave 14 French monolinguals, 11 bilinguals and 10 who were exposed to an Asian tone language. In the group of 4-5-year-olds, 25 were French monolinguals, 12 were bilinguals and 10 had been exposed to an Asian tone language. Finally, in the group of 5-6-year-olds, 16 were French monolinguals, 11 were bilinguals and 22 were exposed to an Asian tone language.

A repeated-measures analysis of variance (ANOVA) was conducted to assess whether response accuracy varied according to the within-factor Contrast Type (Consonants versus Tones) and Trial Type (Change versus No Change), and to the between-factor Age Group (3 school year groups) and Language Group (Exposure to a Tone Language versus Exposure to a second Non-Tone Language versus Exposure to French only). This analysis revealed a main effect of Contrast Type $[F(1,125)=17.28, p$ $<.001, \eta^{2}=.12$ ] indicating that overall higher accuracy was observed for tones (mean = 0.90 , standard error $(\mathrm{SE})=0.10$ ) than consonants (mean $=0.84, \mathrm{SE}=0.13$ ). The analysis of the interactions revealed a significant interaction between Contrast Type and Language group $\left[F(2,125)=3.11, p=.048, \eta^{2}=.05\right]$, Trial Type and Age group $[F(2,126)$ $\left.=8.45, p<.001, \eta^{2}=.12\right]$, and a three-way interaction between Age group, Contrast Type, and Trial Type $\left[F(2,126)=6.66, p=.002, \eta^{2}=.10\right]$.

Figure 2 represents the response accuracy for the Consonant and Tone conditions according to language group illustrating the interaction between Contrast Type and Language group. Post-hoc tests for this interaction indicate that children exposed to an Asian tone language show significantly higher accuracy for tones (mean = $0.92, \mathrm{SE}=0.18$ ) compared to monolingual French children (mean $=0.87, \mathrm{SE}=0.16, p$ $=.031$ ). Moreover, when comparing Contrast Types, children exposed to an Asian tone language and bilingual children not exposed to any tone language, but not French monolinguals, show significantly higher accuracy for tones than for consonants (mean difference $=0.11,0.06,0.02$, respectively, and $p<.001, p=.033$ and $p=.40$ ). 


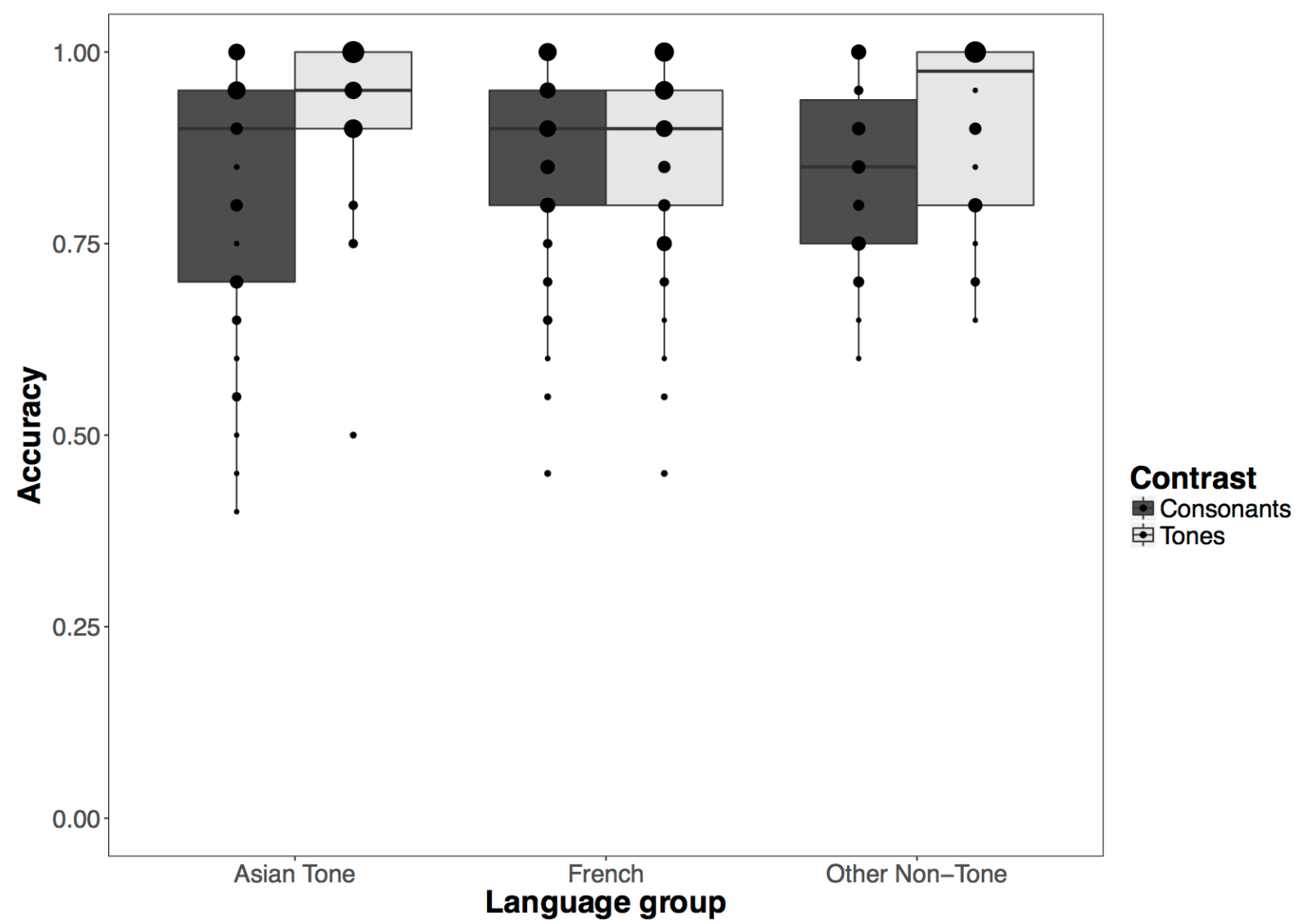

Figure 2. Box plots of response accuracy in the Consonant (dark grey bars) and Tone (light grey bars) conditions according to the three groups of languages (Asian Tone, French and Other non-tone language). The three horizontal lines represent the 25th, 50th, and 75th percentiles, respectively, and approximately 95\% of the data are expected to lie between the vertical bars. The size of the dots is proportional to the number of overlapping observations: $\mathrm{N}=1,5,10$ to 15 .

Figure 3 displays the proportion of correct responses for Change trials and NoChange trials for Consonant and Tones according to Age group, illustrating the threeway interaction between Age group, Contrast Type, and Trial Type. Post-hoc tests showed that for Change trials (see Figure 3 left panel) in the Consonant condition, the youngest group (3-4 years) exhibited the lowest scores (mean $=0.75, \mathrm{SE}=0.28$ ) compared to the other two groups (for 4-5 years: mean $=0.87, \mathrm{SE}=0.24, p=.001$; for $5-6$ years: mean $=0.91, \mathrm{SE}=0.24, p<.001)$, that themselves did not differ from each other ( $p$ $=.18$ ). For Tones, the oldest group showed nearly perfect detection and had the highest scores (mean $=0.97, \mathrm{SE}=0.16$ ) compared to the other two groups (for 3-4 years: mean $=0.89, \mathrm{SE}=0.18, p=.001$; for $4-5$ years: mean $=0.90, \mathrm{SE}=0.16, p=.002)$, that themselves did not differ from each other $(p=0.55)$. Interestingly, the youngest and oldest groups showed significantly higher scores for Tones than for Consonants (mean difference $=0.14$ and $0.06, p<.001$ and $p=.03$, respectively). 


\section{Trials}

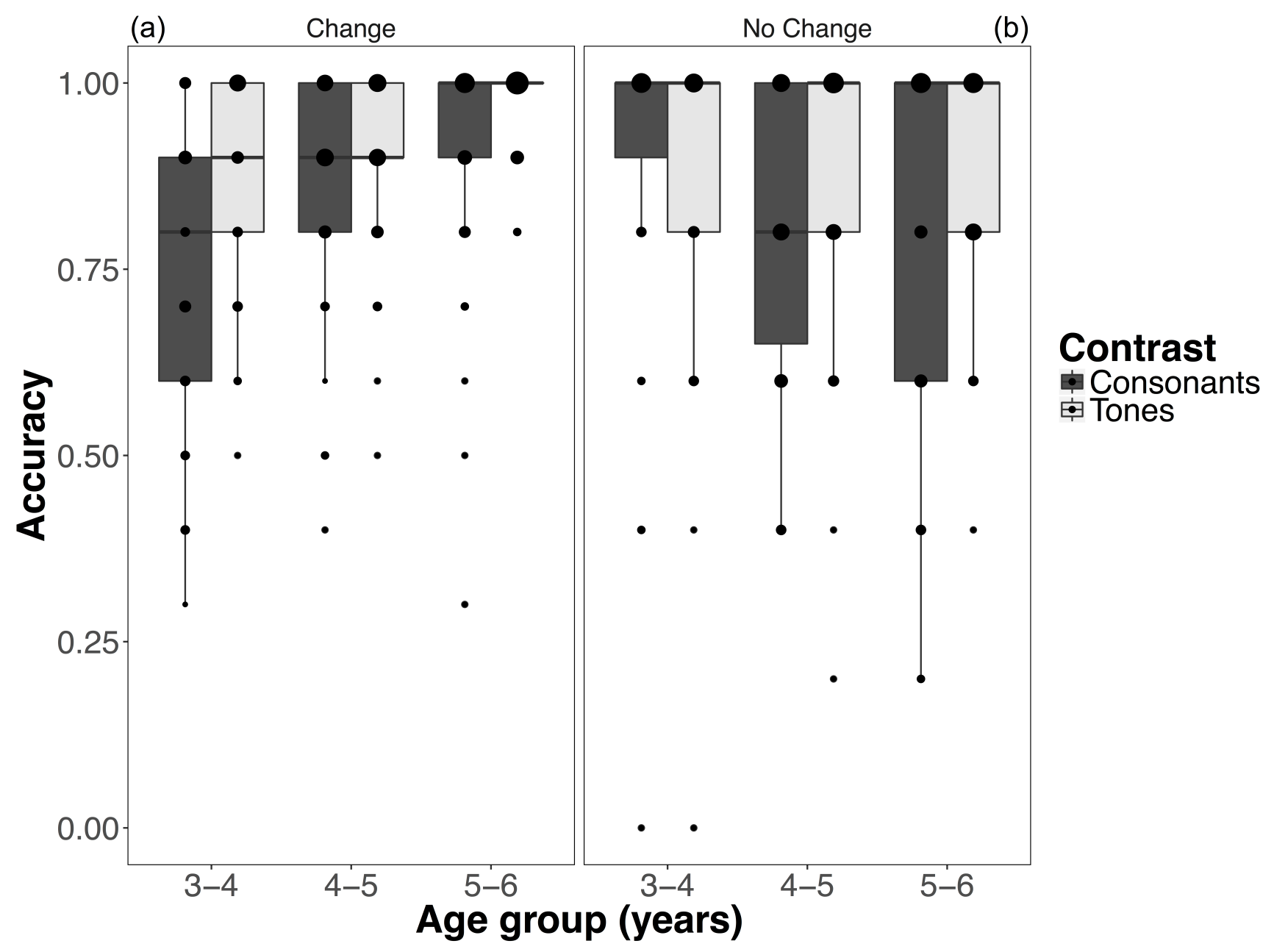

Figure 3. Box plots of response accuracy for Change trials (left panel) and for No-Change trials (right panel) in the Consonant (dark grey bars) and Tone (light grey bars) conditions according to the three age groups. The size of the dots is proportional to the number of overlapping observations: $\mathrm{N}=1,5,10$ to 15 . 
Regarding No-Change trials (see Figure 3 right panel), children of 4-5 years showed significantly more false alarms (i.e., detecting the No-Change trials as Change trials and thus, showing poorer accuracy on No-Change trials) in the Consonant condition than the Tones (mean difference $=0.09, p=.018$, and mean difference $=0.07$, $\mathrm{p}=.055$ for 5-6 years), suggesting that tones lead to fewer mistakes and thus, are somewhat easier to discriminate than consonants. Surprisingly, the youngest group (3-4 years) showed an equivalent level of false alarms for consonants and tones ( $p=.68)$.

When correcting for response bias, i.e., by subtracting the proportion of false alarms on No-Change trials from the proportion of correct detection on Change trials, a repeated-measures ANOVA showed a main effect of Contrast and a significant Contrast Type X Language group interaction leading to the same results regarding the effect of language exposure on consonant and tone detection.

This first analysis suggests that the detection of a consonant change improves between 3-4 years and 4-5 years, but continues to improve for lexical-tones until 5-6 years. Interestingly, the language spoken at home seems to influence the overall accuracy for lexical-tone detection. Children exposed to an additional language other than French are better able to discriminate lexical-tone than consonant contrasts.

A second series of analyses was then run to assess further the effect of increasing exposure to each language category and the effect of age (as a continuous factor) on the accuracy scores. Here, continuous proportions of Exposure to French, to an Asian tone language and to another non-tone language, estimated from the parent questionnaire, were used to predict accuracy in the tasks. For instance, participant \#34 was age 55.57 months and exposed to $42 \%$ of French, $0 \%$ of another non-tone language, and $58 \%$ of an Asian tone language, whereas participant \#104 was 42.07 months and exposed to $92 \%$ of French, $8 \%$ of another Non-Tone Language, and $0 \%$ of an Asian tone language (see Figure 1). Thus, instead of group analyses, this approach takes into account the individual characteristics of each participant to assess whether Age and/or Language exposure (estimated with 3 different proportions) could predict individual performance. Regression analyses were used to model how these four continuous factors contribute to the score variability for consonants on the one hand, and tones on the other.

When predicting the accuracy for Change trials in the Consonant condition, a stepwise regression analysis revealed that Age predicted $13.4 \%$ of the variance ( $p$ $<.001)$. For Change trials in the Tone condition, a stepwise regression analysis revealed that Age also contributed to the model and explained $9 \%$ of the variance $(p<.001)$. Finally, when predicting the accuracy for No-Change trials, or when correcting the scores for response bias, none of the factors selected for the stepwise regression analysis significantly contributed to the model for Consonants or Tones.

These analyses indicate that the discrimination ability of consonant and tone contrasts improves with age and did not show a linear effect of language exposure to a tone language on this ability. 


\section{DISCUSSION}

This study first aimed to examine the perception of both lexical tones and consonants within the same children between 3 and 6 years of age. The results demonstrated that discrimination performance on change trials improves with age for both consonants and tones over the groups of children. As expected, different patterns of development for these two types of contrasts were revealed. Consonant change detection continues to improve until 4-5 years in the present task. This result could simply indicate that children get better at the VRASPAC detection task until 5 years. However, the pattern of improvement is slightly different for the lexical-tone contrasts, suggesting that the present results are not only related to a better understanding of the behavioral procedure with age, but also to the development of phonological processing. Indeed, overall performance continues to improve until 5-6 years of age for lexical-tone discrimination. This slower pattern of development for the detection of lexical-tone contrasts compared to consonants could be related to the slower development for tonological awareness observed in previous studies (Burnham et al., 2011), suggesting different developmental trajectories for consonants and lexical tones. Such differences have also been observed during the second year of life (Liu \& Kager, 2014) further suggesting different processing for consonants and lexical tones (see Nazzi, Poltrock, \& Von Holzen, 2016, for a review on the pattern of development for vowels versus consonants).

When considering both the responses on Change and No-Change trials over age, even though the picture is slightly different, variations in tones seem overall easier to detect than in consonants. The youngest age group (3-4 years) showed better detection of a change in tone than in consonant and did not show any difference in their false alarm rate. One interpretation is that children's responses to lexical tone changes are mainly driven by pitch variations at the acoustic/phonetic level, while their responses to consonant changes are driven more by linguistic/phonological representations that are still developing. Moreover, in this group the number of children exposed to the different languages was fairly well balanced with 10 children exposed to an Asian tone language, 14 to French only and 11 to another second non-tone language. Thus, any difference could not have been to do with sampling. Therefore, the results suggest that tones are easier to process than consonants at 3 years of age. This pattern of response continues to develop with age. Children aged 5-6 years also show higher accuracy when detecting tone versus consonant changes. In parallel, with age, false alarm rates begin to increase for consonants, such that children make more errors with consonants than tones. This could be an indication of an increasing attentional demand for consonants and could be interpreted as indicating that lexical tones are more discriminable than consonants, requiring less specific attention.

The present study also aimed to assess whether and how the language spoken at home could influence children's discrimination of lexical tones and consonants. Previous studies suggest that according to the linguistic categories present in the child's native language, tones start to be processed on a more phonological basis with age (Burnham 
et al., 2011; Burnham \& Francis, 1997). Not surprisingly, the current results show that children exposed to a tone language at home exhibit better detection of lexical-tone contrasts than consonants. This indicates that children exposed to a tone language are better at detecting pitch variations at the syllable level, when they are similar to their native tonological repertoire, compared to French consonant contrasts that may not belong to their native repertoire. Perhaps more surprisingly, children not exposed to a tone language at home but exposed to several languages (such as Cambodian, Arabic, Wolof, English, Romanian, German or Portuguese) show the same effect. The regression analyses also suggest that the detection of lexical tones does not improve proportionally with exposure to a lexical-tone language, consistent with the fact that bilingual children not exposed to any tone language are also better at detecting lexical tones. This is in line with previous studies suggesting that exposure to various languages enhances sensitivity to prosodic cues (e.g., Bijeljac-Babic et al., 2012). Conversely, children who are exposed only to French do not show any difference in the detection of non-native lexical-tone contrasts and French consonants. This group of monolingual children also shows poorer detection of tones than children exposed to an Asian tone language. These results are in line with previous studies showing that non-native listeners are able to detect pitch variations within syllables in simple discrimination tasks (e.g., Cabrera et al., 2014) but may perform more poorly than native listeners (Burnham \& Francis, 1997). This could also reflect the rather particular status of tones in speech perception. Pitch variations, even though not lexically relevant, are present in all non-tone languages, as they can convey syntactic units such as propositions or utterances (e.g., in French, at least for questions), attract attention or give emotional information etc. (e.g., Collier, 1975; Nooteboom, 1997). However, the different pattern of results between French monolinguals and bilinguals, bilingual in either a tone/non-tone language, also suggests that not only does specific exposure to a tone language affect the responsiveness to pitch variations but also exposure to any type of language using prosodic variations at the lexical level to a greater extent than French. How a language uses acoustic information to signal lexical contrast, will likely influence the function attributed to pitch variations and influence phonological development.

Finally, the fact that monolingual French children do not improve with age at detecting a contrast type belonging to their phonological repertoire is rather surprising. Even though monolingual French children show similar detection scores for tones and consonants in the present study, they may not process these contrasts at the same level of processing (acoustic/phonetic versus linguistic/phonological). Previous studies have observed that French adults' perception of tones is mainly driven by the acoustics (physical properties) of the tones, in contrast to Mandarin listeners who are instead biased by the phonological value of tone contours (Hallé et al., 2004). Thus, it is possible that in the present task, tones were easy to discriminate at a general acoustic/phonetic basis, reaching comparable levels of detection as consonants, which were themselves processed in a more phonological fashion. It remains for future research to determine whether French children improve in their detection of native consonant contrasts with 
age, but not with non-native lexical tone contrasts by using perceptual tasks that are better able to disentangle the role of acoustic versus phonological processing.

The present behavioral procedure also limits the conclusions that can be made regarding the discrimination of the different phonetic contrasts used in the task. Indeed, the low number of trials used for each pair of speech stimuli prevents comparison between different contrasts, such as place of articulation versus voicing, or pitch height versus pitch contour. Previous studies have shown that discrimination abilities vary according to the speech contrast used in the task (e.g., Cabrera et al., 2014; Hallé et al., 2004; Narayan, Werker, \& Beddor, 2010). The present study used the pitch contrast between falling and rising tones which is usually easier for non-tone language listeners as these pitch variations also convey communicative cues in non-tone languages. Future studies should compare performance between several contrasts to better understand how listeners organize the speech signal to develop a phonological system. Finally, even though the present results reveal an influence of exposure to a lexical-tone language or more generally to a second language, on the processing of lexical tones versus consonants, future studies should recruit more narrowly defined bilingual populations (e.g., children exposed to Mandarin or Cantonese) and consider using native lexical-tone stimuli.

To conclude, the present study provides new evidence that the perception of lexical tones and consonants follows a different developmental trajectory between 3 and 6 years. Specifically, the results suggest that overall 3 and 6 years of age, lexical tones are perceived more accurately than consonants. Instead, the perception of lexical tones seems to be determined by both language-specific influences and nonlinguistic/auditory processing during childhood. However, the results also suggest that as a result of exposure to a tone-language, pitch variations at the syllable level acquire a more specific status, such that they may be processed phonologically. Moreover, exposure to numerous languages seems to enhance the processing of prosodic cues for speech. 


\section{FUNDING}

JB was supported by the Agence Nationale de la Recherche (ANR-12-ISH2- 0001-01).

\section{ACKNOWLEDGMENTS}

The authors wish to thank the schools in the XIIIe arr of Paris and all the children who participated in the study, as well as Bronwen Evans for help in manuscript preparation.

\section{REFERENCES}

Abboub, N., Bijeljac-Babic, R., Serres, J., \& Nazzi, T. (2015). On the importance of being bilingual: Word stress processing in a context of segmental variability. Journal of Experimental Child Psychology, 132, 111-120.

Bent, T., Bradlow, A. R., \& Wright, B. A. (2006). The influence of linguistic experience on the cognitive processing of pitch in speech and nonspeech sounds. Journal of Experimental Psychology Human Perception and Performance, 32(1), 97-103.

Bertelson, P., Gelder, B. de, Tfouni, L. V., \& Morais, J. (1989). Metaphonological abilities of adult illiterates: New evidence of heterogeneity. European Journal of Cognitive Psychology, 1(3), 239-250.

Bertoncini, J., Serniclaes, W., \& Lorenzi, C. (2009). Discrimination of speech sounds based upon temporal envelope versus fine structure cues in 5-to 7-year-old children. Journal of Speech, Language, and Hearing Research, 52(3), 682-695.

Bijeljac-Babic, R., Serres, J., Höhle, B., \& Nazzi, T. (2012). Effect of bilingualism on lexical stress pattern discrimination in French-learning infants. PLoS One, 7(2), e30843.

Burnham, D., \& Francis, E. (1997). The role of linguistic experience in the perception of Thai tones. In A.S. Abramson (Ed.). Southeast Asian linguistic studies in honour of Vichin Panupong (Science of Language, Vol. 8) (pp. 29-47). Bangkok: Chulalongkorn University Press.

Burnham, D., Kim, J., Davis, C., Ciocca, V., Schoknecht, C., Kasisopa, B., \& Luksaneeyanawin, S. (2011). Are tones phones? Journal of Experimental Child Psychology, 108(4), 693-712.

Burnham, D., \& Mattock, K. (2007). The perception of tones and phones. In M. J. Munro., \& O. -S. Bohn (Eds.), Language experience in second language speech learning. In honor of James Emil Flege (pp. 259-280). Amsterdam: John Benjamins (Series: Language Learning and Language Teaching).

Burnham, D., Singh, L., Mattock, K., Woo, P. J., \& Kalashnikova, M. (2017). Constraints on Tone Sensitivity in Novel Word Learning by Monolingual and Bilingual Infants: Tone properties are more influential than tone familiarity. Frontiers in Psychology, 8:2190.

Burns, T. C., Yoshida, K. A., Hill, K., \& Werker, J. F. (2007). The development of phonetic representation in bilingual and monolingual infants. Applied Psycholinguistics, 28(03), 455-474.

Cabrera, L., Tsao, F.-M., Gnansia, D., Bertoncini, J., \& Lorenzi, C. (2014). The role of spectro- 
temporal fine structure cues in lexical-tone discrimination for French and Mandarin listeners. The Journal of the Acoustical Society of America, 136(2), 877-882.

Cabrera, L., Tsao, F.-M., Liu, H.-M., Li, L.-Y., Hu, Y.-H., Lorenzi, C., \& Bertoncini, J. (2015). The perception of speech modulation cues in lexical tones is guided by early languagespecific experience. Frontiers in Psychology, 6:1290.

Caramazza, A., \& Yeni-Komshian, G. H. (1974). Voice onset time in two French dialects. Journal of Phonetics, 2, 245.

Cho, T., \& Ladefoged, P. (1999). Variation and universals in VOT: Evidence from 18 languages. Journal of Phonetics, 27(2), 207-229.

Collier, R., \& Hart, J. (1975). The role of intonation in speech perception. In A. Cohen \& S. G. Nooteboom (Eds.), Structure and process in speech perception, (pp. 107-121). Heidelberg: Springer-Verlag.

Eisenberg, L. S., Martinez, A. S., \& Boothroyd, A. (2004). Perception of phonetic contrasts in infants: Development of the VRASPAC. In R. T. Miyamoto (Ed.), International congress series: Vol. 1273. Cochlear implants (pp. 364-367). Amsterdam: Elsevier.

Gandour, J. (1981). Perceptual dimensions of tone: Evidence from Cantonese. Journal of Chinese Linguistics, 9(1), 20-36.

Gandour, J. T., \& Harshman, R. A. (1978). Crosslanguage differences in tone perception: A multidimensional scaling investigation. Language and Speech, 21(1), 1-33.

Grosjean, F. (2010). Bilingual: Life and reality. Cambridge, MA: Harvard University Press.

Hallé, P. A., Chang, Y.-C., \& Best, C. T. (2004). Identification and discrimination of Mandarin Chinese tones by Mandarin Chinese vs. French listeners. Journal of Phonetics, 32(3), 395421.

Holt, R. F., \& Lalonde, K. (2012). Assessing toddlers' speech-sound discrimination. International Journal of Pediatric Otorhinolaryngology, 76(5), 680-692.

Khouw, E., \& Ciocca, V. (2007). Perceptual correlates of Cantonese tones. Journal of Phonetics, $35(1), 104-117$.

Kuhl, P. K., Stevens, E., Hayashi, A., Deguchi, T., Kiritani, S., \& Iverson, P. (2006). Infants show a facilitation effect for native language phonetic perception between 6 and 12 months. Developmental Science, 9(2), F13-F21.

Kuhl, P. K., Williams, K. A., Lacerda, F., Stevens, K. N., \& Lindblom, B. (1992). Linguistic experience alters phonetic perception in infants by 6 months of age. Science, 255(5044), 606-608.

Liu, H.-M., Chen, Y., \& Tsao, F.-M. (2014). Developmental changes in mismatch responses to Mandarin consonants and lexical tones from early to middle childhood. PloS One, 9(4), e95587.

Liu, L., \& Kager, R. (2014). Perception of tones by infants learning a non-tone language. Cognition, 133(2), 385-394. 
Liu, L., \& Kager, R. (2017). Perception of tones by bilingual infants learning non-tone languages. Bilingualism: Language and Cognition, 20(3), 561-575.

Martinez, A., Eisenberg, L., Boothroyd, A., \& Visser-Dumont, L. (2008). Assessing speec pattern contrast perception in infants: Early results on VRASPAC, Otology and Neurotology, 29, 183-188.

Mattock, K., \& Burnham, D. (2006). Chinese and English infants' tone perception: Evidence for perceptual reorganization. Infancy, 10(3), 241-265.

Mattock, K., Molnar, M., Polka, L., \& Burnham, D. (2008). The developmental course of lexical tone perception in the first year of life. Cognition, 106(3), 1367-1381.

Narayan, C. R., Werker, J. F., \& Beddor, P. S. (2010). The interaction between acoustic salience and language experience in developmental speech perception: Evidence from nasal place discrimination. Developmental Science, 13(3), 407-420.

Nazzi, T., Poltrock, S., \& Von Holzen, K. (2016). The Developmental Origins of the Consonant Bias in Lexical Processing. Current Directions in Psychological Science, 5(4), 291-296.

Nooteboom, S. (1997). The prosody of speech: melody and rhythm. The Handbook of Phonetic Sciences, 5, 640-673.

Polka, L., \& Werker, J. F. (1994). Developmental changes in perception of nonnative vowel contrasts. Journal of Experimental Psychology: Human Perception and Performance, 20(2), 421-435.

Ryalls, J., \& Larouche, A. (1992). Acoustic integrity of speech production in children with moderate and severe hearing impairment. Journal of Speech, Language, and Hearing Research, 35(1), 88-95.

Serniclaes, W. (1987). Etude expérimentale de la perception du trait de voisement des occlusives du français. Unpublished Doctoral Thesis. Université Libre de Bruxelles.

Singh, L., Goh, H. H., \& Wewalaarachchi, T. D. (2015). Spoken word recognition in early childhood: comparative effects of vowel, consonant and lexical tone variation. Cognition, $142,1-11$.

Singh, L., Hui, T. J., Chan, C., \& Golinkoff, R. M. (2014). Influences of vowel and tone variation on emergent word knowledge: a cross-linguistic investigation. Developmental Science, 17(1), 94-109.

Skoruppa, K., Pons, F., Christophe, A., Bosch, L., Dupoux, E., Sebastián-Gallés, N., ... Peperkamp, S. (2009). Language-specific stress perception by 9 -month-old French and Spanish infants. Developmental Science, 12(6), 914-919.

Sundara, M., Polka, L., \& Molnar, M. (2008). Development of coronal stop perception: Bilingual infants keep pace with their monolingual peers. Cognition, 108(1), 232-242.

Vance, T. J. (1976). An experimental investigation of tone and intonation in Cantonese. Phonetica, 33(5), 368-392.

Werker, J. F., \& Tees, R. C. (1983). Developmental changes across childhood in the perception 
of non-native speech sounds. Canadian Journal of Psychology/Revue Canadienne de Psychologie, 37(2), 278.

Werker, J. F., \& Tees, R. C. (1984). Cross-language speech perception: Evidence for perceptual reorganization during the first year of life. Infant Behavior and Development, 7(1), 49-63.

Yeung, H. H., Chen, K. H., \& Werker, J. F. (2012). When does native language input affect phonetic perception? The precocious case of lexical tone. Journal of Memory and Language, 68(2), 123-139.

Zhang, S. C. (2012). Voicing and Devoicing Rules in East and Southeast Asian Languages. Unpublished Doctoral Thesis. Wayne State University. 